\title{
$\begin{array}{llllllll}\mathrm{R} & \mathrm{E} & \mathrm{S} & \mathrm{E} & \mathrm{N} & \mathrm{H} & \mathrm{A} & \mathrm{S}\end{array}$
}

- controladas pelos Estados Unidos e orientadas por critérios econômicos neoclássicos - tem sido capaz de forçar, progressivamente, o fim de políticas inclusivas de desenvolvimento econômico, social e urbano. E como impõe uma política internacional contra a pobreza através do que Davis denomina "Triângulo de Ferro". Profissionais transnacionais baseados em ministérios governamentais-chave, especialmente finanças, agências de desenvolvimento lateral e multilateral e Ongs internacionais, promovem políticas de erradicação da pobreza, visando a democratização, a ajuda mútua, o desenvolvimento do capital social e o fortalecimento da sociedade civil. Sua sustentação institucional no terceiro mundo são Ongs locais e regionais.

$\mathrm{Na}$ prática, esses arranjos, tal como as organizaçôes patrocinadoras da luta contra a pobreza nos Estados Unidos dos anos 1960, são "brilhantes em cooptar as lideranças locais, bem como em homogeneizar o espaço ocupado tradicionalmente pela esquerda ... Salvo raras exceções, a revolução da sociedade civil tem conduzido à burocratização e ao enfraquecimento dos movimentos sociais urbanos".

É digno de nota que as agências e seus operadores locais têm sido muito eficazes em combinar discursos acirrados e ações conservadoras. A defesa da autoajuda e do empreendedorismo, por exemplo, ao invés de promover uma "economia solidária" e o desenvolvimento autônomo, não fazem mais que aumentar a concorrência entre os pobres, radicalizando a economia de mercado e legitimando-a. O arranjo promovido pelas agências internacionais elimina, então, a perspectiva de qualquer saída de tipo socialdemocrática. Seus funcionários e representantes locais agem, agora, tal qual funcionários coloniais do passado.

O fenômeno da urbanização mundial e da expansão da pobreza, mais que desconhecimento, revela o cinismo e a ausência de perspectivas do pensamento dominante, que, antes de estimular políticas eficazes de luta contra a pobreza e a precariedade urbana, prevê, para um futuro próximo, a escalada dos conflitos nas cidades. Portanto, prepara-se o caminho para a militarização da "questão urbana", que não é senão a existência de um "exército de reserva que espera lugar no processo de trabalho tornando-se estigmatizado: uma massa redundante permanente". Assim, o processo de favelização mundial é "a real crise do capitalismo".

\section{UM MURAL PARA \\ A DOR: MOVIMENTOS CÍVICO-RELIGIOSOS POR JUSTIÇA E PAZ}

Patricia Birman e Márcia Pereira Leite (orgs.)

Porto Alegre: Ed. UFRGS/Pronex-CNPq, 2004.

Lidia Medeiros

UERJ

O vocabulário utilizado para designar os fenômenos relativos ao amplo conjunto de eventos usualmente designados como violência urbana vem sofrendo, ao longo do tempo, uma lenta e gradual transformação. Os debates em torno do tema, sobretudo no Rio de Janeiro, têm cotejado temas dos mais distintos: crime, banditismo, marginalidade, ação da polícia, controle social, desordem, vadiagem, linchamento, homicídios, entre outros. A partir do início da década de 1990, a visão do Rio como uma "cidade partida", conforme nos informa Zuenir Ventura em Cidade partida (1994), marcada pela separação e pela segregação, passa a tomar conta das interpretaçôes sobre o fenômeno e do imaginário social dos moradores da cidade. As noções que passaram a povoar noticiários, textos acadêmicos e conversas informais foram as de terror, crueldade, tráfico de drogas, guerra (ou "metáfora da guerra" (Márcia da Silva Pereira Leite, Para além da metáfora da guerra, 2001), violência policial, conflito, criminalidade violenta, sociabilidade violenta. Essa mudança de foco nas preocupaçôes a respeito da tematização do problema diz respeito ao que Machado da Silva (Sociabilidade violenta, 2004, p.291-2) identifica como "uma das expressões atuais do desenvolvimento histórico do individualismo, ou seja, uma de suas formas cristalizadas", que resulta nas formas contemporâneas de "organização social das relações de força que são legal e administrativamente definidas como crime comum violento".

Paralelamente, as análises relativas aos movimentos sociais apontam para uma mudança de foco nas suas formas de tematização e ação. De um perfil reivindicativo e combativo, que cultivava uma "cultura política de protesto" vinculada às esquerdas tradicionais (cf. Birman, neste volume) na luta contra uma situação de marginalidade social, os movimentos sociais pós-ditadura militar passaram a preocupar-se com a supera- 
ção da precariedade econômico-social das populações mais empobrecidas. Reúnem-se, então, em um mesmo campo de ação, grupos religiosos e laicos vinculados às reivindicações em torno de direitos sociais e práticas assistenciais, filantrópicas e projetos caritativos. Esses novos movimentos, que têm nas Ongs um elemento aglutinador, vêm se reunindo em torno de questôes mais amplas, como por exemplo a Ação da Cidadania Contra a Fome e a Miséria (de âmbito nacional) e os movimentos em defesa das populações pobres e/ou marginalizadas (de âmbito local, Rio de Janeiro). Esses movimentos, sobretudo aqueles localizados no Rio de Janeiro, procuravam e procuram responder aos dilemas colocados pela visão de uma cidade dividida e em guerra, em busca de elementos que viabilizassem a reunião em torno de um objetivo comum, no caso em questão, a possibilidade de construção da paz.

É nesse contexto que a problematização dos aspectos de ordem subjetiva relativos ao tema da violência se colocam nos relatos sobre o seqüestro do ônibus 174 e o principal movimento de reação a este evento, a organização do Mural da Dor, articulada pela entidade Viva Rio. No ano 2000, Sandro do Nascimento fez os passageiros de um ônibus reféns durante quatro horas e meia em uma das principais ruas da zona sul da cidade do Rio de Janeiro. O evento teve ampla cobertura na mídia e culminou na morte do seqüestrador e de uma das vítimas, Geisa. O Mural da Dor foi uma manifestação que consistiu na construção de um imenso painel no Largo da Carioca, no qual, durante três dias, familiares e amigos afixaram, livremente, retratos e relatos sobre vítimas da violência na cidade. Todos os que ali se reuniram puderam partilhar sua dor, se solidarizar e reivindicar soluçóes para seus casos particulares e para o problema da violência que acomete a cidade como um todo.

Um mural para a dor: movimentos civico-religiosos por justiça e paz, organizado por Patricia Birman e Márcia Pereira Leite, converge exatamente para o enfrentamento da violência pelos novos movimentos sociais, abrindo um fecundo campo de investigação sobre o problema. O livro traz para o campo de discussão da sociologia, aspectos de ordem subjetiva implicados naquilo que se convencionou chamar de "violência urbana”. Os textos dão voz e vida àquelas personagens usualmente tratados como "destituídas de sua dignidade e valor como pessoas e como cidadâs" (p.10) e gi- ram em torno de eventos e indivíduos cuja representação no espaço público e na literatura especializada não é muito recorrente.

Embora girando em torno de um mesmo eixo as manifestações cívico-religiosas decorrentes do seqüestro do ônibus 174 -, os autores desenvolvem análises sobre aspectos distintos. O livro está organizado em três partes e conta com oito artigos de pesquisadores que participaram direta ou indiretamente (como interlocutores) da pesquisa "Mural da Dor: movimentos sociais, religião e política no Rio de Janeiro", desenvolvida no âmbito do Núcleo de Religião e Política do Programa de Apoio a Núcleos de Excelência (Pronex) - Movimentos Religiosos no Mundo Contemporâneo. O movimento "Basta! Eu Quero Paz" e o Mural da Dor, especialmente este último, são os movimentos aos quais os autores se remetem ao longo de suas reflexões e se constituíram como "cenários de protesto, manifestações da dor e de solidariedade" (p.13); lugares de reunião nos quais familiares, amigos e público em geral poderiam manifestar sua dor, saudade e prestar reverência às vítimas da violência, além de reivindicar justiça e reparação.

A primeira parte, intitulada "Da morte e da violência", conta com os artigos de Marc-Henri Piault ("Da violência, ou como se livrar dela. A propósito do seqüestro de um ônibus no Rio de Janeiro"), que realiza uma análise das condições a partir das quais foi possível construir a vitimização social de Sandro. Essa ressemantização da imagem de Sandro do Nascimento ocorre em um contexto no qual a espetacularização do seqüestro do ônibus 174 foi fundamental para a arquitetura das performances durante e depois do evento. $\mathrm{O}$ autor argumenta que os acontecimentos de junho de 2000 colocam em questão o equilíbrio de uma sociedade que reivindica, "paradoxalmente, uma unanimidade dos confrontos que a dilaceram" (p.65). A questão que se coloca é: como vencer esse paradoxo? Ou ainda, eventos como os relatados nesse volume são capazes de gerar reações que levem a uma superação?

Rosilene Alvim e Eugênia Paim, em "Muitos nomes, muitas vidas. Em busca da memória de Sandro do Nascimento", reconstituem os relatos sobre a vida e a trajetória do seqüestrador, desde suas origens até sua morte. As autoras chamam a atenção para o fato de o seqüestro e o protagonismo de Sandro neste 
evento reatualizarem e apresentarem um desfecho para um outro acontecimento traumático na história recente da cidade, marcado por extrema violência: a Chacina da Candelária. Com base em depoimentos, matérias de jornais e trechos de livros, é construída uma "imagem" de Sandro que se caracteriza por se tratar de um "relato de vida ao contrário" (p.83). Sua existência e visibilidade só acontecem quando toma parte em um episódio no qual protagoniza, como algoz, o "espetáculo" da violência urbana. As autoras chamam a atenção do leitor para a fluidez da identidade de Sandro - que foi Alex Mancha, Sérgio, Alessandro, Mancha da Candelária -, que traduziria as flutuações biológicas, sociais e geográficas que marcaram sua trajetória, e teria marcado sua "encenação" e movimento corporal durante o seqüestro do ônibus. $\mathrm{O}$ desfecho da vida de Sandro reflete o que foi sua vida: a absolvição dos policiais que provocaram sua morte revela que, mesmo com toda a exposição e construção de sua vida como vítima das profundas desigualdades sociais que marcam nossa sociedade, Sandro permanece um anônimo, um "associal" (p.85). As tentativas de tirar os meninos de rua da sua situação de invisibilidade, seja através de ações inclusivas, seja pela força, trarão solução para o problema?

"Rituais para a dor. Política, religião e violência no Rio de Janeiro", de Ludmila da Silva Catela e Regina Reyes Novaes, trata da produção da dor pública presente no movimento "Basta! Eu Quero Paz" e no Mural da Dor, através da análise de "sua linguagem, performances e símbolos" como forma de "identificar ambivalências, paradoxos e novas formas e níveis de participação em torno do drama contemporâneo denominado genericamente como "violência urbana" (p.110). Essa análise é cotejada pelas reflexões a respeito da morte na sociedade moderna, como interdito e como crime - na sua versão violenta -, elaboradas, respectivamente, por Ariès (1997), em História da morte no Ocidente, e Elias (2001), em A solidão dos moribundos. A violência midiatizada provocou uma série de conseqüências imprevistas, como a mudança de status de Geisa - a morte de uma moradora de favela tornouse um fato extraordinário; a espetacularização da morte faz com que o fato deixe de ser apenas um dado nas estatísticas sobre violência e uma peça de ficção; a morte ao vivo provoca um sentimento coletivo de dor e as condições necessárias para os rituais que tentarão exor- cizá-la. As autoras analisam, com base nessas referências, as representações da morte e do sofrimento presentes no Mural da Dor. De um evento que deve ser silenciado e restrito à esfera privada, como convém à sua configuração na sociedade moderna, a morte adquire então um sentido público e é "desprivatizada" através da conjugação de "recursos simbólicos advindos tanto da religiosidade popular quanto das formas de manifestar indignaçōes políticas" (p.116). Essa perspectiva de análise nos coloca diante da qualidade heurística das análises a respeito do papel das diversas dimensões da subjetividade na ação social.

A segunda parte do volume, "Conflitos e movimentos”, inicia com o artigo de Márcia Pereira Leite, "As mães em movimento". A autora analisa os papéis desempenhados, as apropriações, os conflitos e as negociações em torno das formas de participação das "mães" no Mural da Dor. Sua presença na manifestação, apesar de considerada essencial pelo Viva Rio em virtude de sua legitimidade e do apelo ao perdão que sua imagem evoca, se deu em meio a contradições. Os discursos sobre a violência e demandas por justiça para seus filhos foram diluídos em um apelo pela homogeneização em torno da paz e do perdão, resultando em um ato que "envolveu, sobretudo, uma dimensão moral, não politizada, de tratar a violência na cidade do Rio de Janeiro" (p.188). O texto conclui revelando que os conflitos em torno da participação dos policiais mortos em serviço, do caráter apolítico do movimento e da nãoincorporação no movimento dos discursos sobre violência próprios a cada grupo levaram à formação de um novo movimento: as Mães do Rio. Quais são os desafios e as conquistas dos novos movimentos sociais, sobretudo em virtude das disputas por poder e legitimidade que enfrentam? É a essa questão fundamental a que o texto remete.

Ruth Helena de Souza Britto analisa em, "Sobre as repercussóes na Rocinha da morte de Geisa”, as percepçōes e interpretaçōes entre os moradores da favela sobre o seqüestro do ônibus 174 , que culminou na morte da moradora citada no título do artigo. Evidencia, na reconstrução dos depoimentos sobre o evento, a disputa por legitimidade entre líderes e moradores da favela e grupos sociais externos. Percebe a dissonância entre o relato jornalístico, que constrói uma identidade de vítima para Geisa (para além da de moradora da 
favela), e os depoimentos dos entrevistados, que não reconhecem o pertencimento de Geisa à "comunidade" em virtude do pouco tempo de residência e do seu desconhecimento entre os líderes e moradores mais antigos: "os moradores da Rocinha questionam a legitimidade do status adquirido por Geisa como vítima "ícone", enquanto o "asfalto" parece, fechando com a versão da mídia, não ter dúvidas sobre isso" (p.211). $\mathrm{Na}$ verdade, essa oposição tem um caráter didático (não é à toa): o que se pretende é objetar contra a imagem da favela como promotora da violência, isto é, contra o velho mito do pobre como fonte dos males da sociedade, e ressaltar que a pior violência é aquela perpetrada pelo próprio "asfalto" contra as favelas. Ao mesmo tempo, os informantes optam por silenciar sobre a violência que acontece dentro de sua própria "comunidade". Mais uma vez o campo de disputas entre os novos movimentos sociais se apresenta ao colocar em lados opostos Ongs (de fora) e lideranças/moradores (de dentro).

A terceira e última parte, "Civismo e participação humanitária", conta com o artigo de Patrícia Birman, "Movimentos cívico-religiosos no Rio de Janeiro e alguns de seus impasses: o caso do Mural da Dor", no qual realiza uma análise densa a respeito dos movimentos sociais de novo tipo, que têm como principal motivação a defesa de populações pobres e/ou marginalizadas, sobretudo a partir da prática cívico-religiosa de reação à violência praticada contra elas. Percorrendo o caminho da experiência desenvolvida pela Ong Viva Rio desde sua fundação, mas com ênfase na campanha "Basta! Eu Quero Paz" e no Mural da Dor, a autora traça um panorama de três momentos dessa nova modalidade de protesto. O Viva Rio surge, no início da década de 1990, procurando responder aos desafios colocados pela idéia de guerra entre as duas partes da "cidade partida", marcada pela política do extermínio e da segregação. Como orientação política de sua ação, a Ong se coloca contrariamente aos movimentos de protesto das esquerdas tradicionais e procura incorporar formas de ação e recursos freqüentemente desprezados, oriundos de associações filantrópicas, religiosas e de ajuda mútua, procurando, com isso, "romper com a clivagem entre 'caridade' e 'direitos" (p.228). Nesse contexto, assume grande relevância o papel dos movimentos religiosos, na forma de "união mística entre pessoas e grupos" (p.232) e não mais na sua vertente de engajamento políticoreligioso, como a Teologia da Libertação, muito popular no Brasil, sobretudo nas décadas de 1970 e 1980. É nesse contexto que a campanha do "Basta!" e do Mural da Dor, açôes inéditas e inovadoras no Brasil, se inscrevem como formas de expressão ritualística no espaço público da dor e do luto. Mais especificamente, os dois eventos procuravam dar vazão aos sentimentos de dor, medo e perplexidade que as cenas de "sofrimento à distância", divulgadas pela mídia por ocasião do seqüestro do ônibus 174 , provocaram no conjunto da sociedade. Na avaliação da autora, a atuação do Viva Rio nos eventos analisados é passível de crítica: a Ong falhou na qualificação do chamado à paz proposto nos movimentos; os grupos convidados a participar das manifestaçôes foram incentivados a deixar de lado suas diferenças e as disputas em torno das práticas humanitárias e escolhas políticas; a incorporação dos policiais mortos gerou polêmica, por produzir uma impossibilidade de distinção entre vítimas e algozes, entre sociedade civil e Estado (considerando que esse era um dos interpelados nos protestos por justiça). Diante disso, cabe questionar a efetividade de ações nas quais a dimensão religiosa se sobrepõe à dimensão política.

"Da pacificação - o 'Basta! Eu Quero Paz' e as inscrições artísticas”, de Márcia Leitão Pinheiro, aborda a participação de artistas que moram ou atuam em favelas/comunidades. São três os grupos analisados: Grupo Cultural Afro Reggae, grupo teatral Nós do Morro e grupo musical evangélico Radicalizando, Evangelizando e Politizando (REP). Todos percebem sua atuação como forma de denúncia da situação que as favelas vivem e oportunidade de transformação dessa realidade. A participação desses grupos no "Basta!" teve em comum o apelo à paz e o teor de denúncia. Desse modo, sua apresentação no movimento se traduziria em "uma via de ligação entre as favelas e o restante da cidade, por compreender fluxos de serviços públicos, de pessoas e de bens culturais que redefiniriam o estatuto da periferia no espaço urbano" (p.290).

A crescente importância dos grupos artísticos e culturais para o desenvolvimento do trabalho comunitário nas favelas/comunidades e periferias é inquestionável. É preciso, no entanto, realizar investigações mais detalhadas a respeito desses movimentos de con- 
teúdo cultural, com a finalidade de avaliar se seriam realmente capazes de forjar a ligação pretendida entre favelas e o restante da cidade.

Peter Lucas, em "O Mural da Dor e a ética da memória”, discute a pertinência de pensar esse evento como algo que formou ou reforçou a idéia de uma comunidade ética, isto é, uma comunidade baseada em "relações densas entre pessoas conectadas pela cultura e pela história” (p.318), partilhando uma moral da preocupação e uma ética do cuidado. Embora o seqüestro do ônibus 174 tenha maiores possibilidades de cumprir o papel de criar essa comunidade ética, na medida em que a proximidade do cotidiano da população e a grande exposição do evento foram capazes de intensificar o senso de pertencimento, o mesmo talvez não possa ser dito do Mural da Dor. Esse evento, apesar de apresentar os elementos simbólicos necessários ao cultivo da comunidade ética, explicitou as profundas tensões e as divisões entre familiares de vítimas da violência, grupos ligados à luta por direitos humanos e suas visões e projetos políticos para o tratamento do problema da violência.

A questão é como forjar e manter uma comunidade ética em uma sociedade marcada por profundas desigualdades sociais, na qual o pleito público pelo debate sobre os direitos humanos e a demanda pela realização de justiça por parte do Estado ficam obscurecidos por um cotidiano de insegurança e violência.

Nesse sentido, o volume traz uma importante contribuição para os debates sobre a violência nas grandes cidades. Ficam expostos os limites e potencialidades dos novos movimentos que colocam esse problema na pauta de discussão pública e procuram desenvolver ações capazes de colaborar para sua resolução.

O livro traz, ainda, um CD-Rom, realizado e organizado por Marc Henri Piault, com imagens do mural organizadas por temas, apresentando os painéis expostos e as vítimas - crianças, mulheres, violência familiar, ação policial, desaparecidos, acidentes de trânsito e policiais mortos. 